\title{
Article \\ Effects of Soil pH on Gaseous Nitrogen Loss Pathway via Feammox Process
}

\author{
Ding Ma ${ }^{1}$, Jin Wang ${ }^{2}$, Jun Xue ${ }^{3}$, Zhengbo Yue ${ }^{2, *}$, Shaofeng Xia ${ }^{3}$, Lei Song ${ }^{3}$ and Hongwen Gao ${ }^{1, *}$ \\ 1 College of Environmental Science and Engineering, Tongji University, Shanghai 200092, China; \\ 1610377@tongji.edu.cn \\ 2 School of Resources and Environmental Engineering, Hefei University of Technology, Hefei 230009, China; \\ sophiawj@hfut.edu.cn \\ 3 Hefei Municipal Design \& Research Institute Co., Ltd., Hefei 230009, China; xueyeah2020@163.com (J.X.); \\ xshf1225@163.com (S.X.); songlei3424@163.com (L.S.) \\ * Correspondence: zbyue@hfut.edu.cn (Z.Y.); hwgao@tongi.edu.cn (H.G.)
}

Citation: Ma, D.; Wang, J.; Xue, J.; Yue, Z.; Xia, S.; Song, L.; Gao, H. Effects of Soil pH on Gaseous Nitrogen Loss Pathway via Feammox Process. Sustainability 2021, 13, 10393. https://doi.org/10.3390/su131810393

Academic Editor: Othmane Merah

Received: 31 August 2021

Accepted: 15 September 2021

Published: 17 September 2021

Publisher's Note: MDPI stays neutral with regard to jurisdictional claims in published maps and institutional affiliations.

Copyright: (c) 2021 by the authors. Licensee MDPI, Basel, Switzerland. This article is an open access article distributed under the terms and conditions of the Creative Commons Attribution (CC BY) license (https:// creativecommons.org/licenses/by/ $4.0 /)$.
Abstract: The application of $\mathrm{N}$ fertilizer is one of the most critical soil acidification factors in China, and soil acidification significantly alters biogeochemical processes such as $\mathrm{N}$ loss. Anaerobic ammonium oxidation coupled with iron reduction (Feammox) is an important biological process for $\mathrm{N}$ loss in natural environments, with the end-products of $\mathrm{N}_{2}, \mathrm{NO}_{2}{ }^{-}$and $\mathrm{NO}_{3}{ }^{-}$. However, the response of Feammox pathways to soil $\mathrm{pH}$ fluctuation has not been thoroughly studied. In the current study, Feammox pathways and microbial communities were explored through a slurry culture experiment with an artificially adjusted $\mathrm{pH}$ combined with a ${ }^{15} \mathrm{~N}$ isotope tracing technique and molecular biotechnology. Results showed significant differences in the gaseous $\mathrm{N}$ loss through Feammox $\left(0.42-0.97 \mathrm{mg} \mathrm{N} \mathrm{kg}^{-1} \mathrm{~d}^{-1}\right)$ under different $\mathrm{pH}$ conditions. The gaseous $\mathrm{N}$ loss pathways were significantly affected by the $\mathrm{pH}$, and Feammox to $\mathrm{N}_{2}$ was the predominant pathway in low-pH incubations. The proportion of $\mathrm{N}$ loss caused by Feammox coupled with denitrification increased as the soil $\mathrm{pH}$ increased. The gaseous $\mathrm{N}$ loss through Feammox increased by $43.9 \%$ when the soil $\mathrm{pH}$ decreased from 6.5 to 5.0. Fe-reducing bacteria, such as Ochrobactrum, Sphingomonas, and Clostridium increased significantly in lower $\mathrm{pH}$ incubations. Overall, this study demonstrated the effects of soil $\mathrm{pH}$ on Feammox pathways and extended the understanding of the $\mathrm{N}$ biogeochemical cycle in acidic soil.

Keywords: Feammox; soil pH; acidification; N loss

\section{Introduction}

With the decrease of arable land area and the decrease of soil fertility, the dependence of agriculture on chemical fertilizers is increasingly serious [1]. The overuse of Nitrogen (N) fertilizer has caused critical environmental problems, such as soil acidification [2]. It was found that the soil $\mathrm{pH}$ in the major grain-producing regions in China has decreased significantly since 1980, and the contribution of fertilization to $\mathrm{H}^{+}$is much higher than that of acid deposition [3]. Soil acidification has adverse effects on terrestrial ecosystems and causes a series of secondary problems, such as the deterioration of soil properties and the activation of heavy metals [4].

A large amount of $\mathrm{N}$ fertilizer is applied to cultivated land in the agricultural production process. However, only about $35 \%$ of the $\mathrm{N}$ can be used by crops, and the remaining $\mathrm{N}$ enters the water and atmosphere through leaching and microbial metabolism [5]. Recently, anaerobic ammonium oxidation coupled with iron reduction (Feammox) has been reported as a novel microbial process involved in the soil $\mathrm{N}$ cycle [6-9]. $\mathrm{NH}_{4}{ }^{+}$is directly oxidized to $\mathrm{N}_{2}$ (Equation (1)), $\mathrm{NO}_{2}{ }^{-}$(Equation (2)), and $\mathrm{NO}_{3}{ }^{-}$(Equation (3)), by microorganisms using $\mathrm{Fe}(\mathrm{III})$ as an electron acceptor under anaerobic conditions in the Feammox process [10,11]. Compared to the nitrification-denitrification process, the Feammox process shortens the $\mathrm{N}$ 
cycle time, and makes a great contribution to $\mathrm{N}$ loss in ecosystems. It was estimated that a loss of 7.8-61.0 $\mathrm{kg} \mathrm{N}$ ha $^{-1} \mathrm{y}^{-1}$ was associated with Feammox, representing $3.9-31.0 \%$ of the $\mathrm{N}$ fertilizer applied to paddy soils in southern China [7].

$$
\begin{array}{cc}
3 \mathrm{Fe}(\mathrm{OH})_{3}+5 \mathrm{H}^{+}+\mathrm{NH}_{4}^{+} \rightarrow 3 \mathrm{Fe}^{2+}+9 \mathrm{H}_{2} \mathrm{O}+0.5 \mathrm{~N}_{2} & \Delta_{\mathrm{r}} \mathrm{G}_{\mathrm{m}}=-245 \mathrm{~kJ} \mathrm{~mol}^{-1} \\
6 \mathrm{Fe}(\mathrm{OH})_{3}+10 \mathrm{H}^{+}+\mathrm{NH}_{4}^{+} \rightarrow 6 \mathrm{Fe}^{2+}+16 \mathrm{H}_{2} \mathrm{O}+\mathrm{NO}_{2}^{-} & \Delta_{\mathrm{r}} \mathrm{G}_{\mathrm{m}}=-164 \mathrm{~kJ} \mathrm{~mol}^{-1} \\
8 \mathrm{Fe}(\mathrm{OH})_{3}+14 \mathrm{H}^{+}+\mathrm{NH}_{4}^{+} \rightarrow 8 \mathrm{Fe}^{2+}+21 \mathrm{H}_{2} \mathrm{O}+\mathrm{NO}_{3}^{-} & \Delta_{\mathrm{r}} \mathrm{G}_{\mathrm{m}}=-207 \mathrm{~kJ} \mathrm{~mol}^{-1}
\end{array}
$$

As an important environmental factor, the soil $\mathrm{pH}$ significantly influences the microbial $\mathrm{N}$ cycle, including the processes of aerobic ammonia oxidation, denitrification, nitrification, and anammox. Denitrification and anammox processes are generally inhibited under acidic conditions, whereas Feammox might favor lower-pH environments as the process needs a ready supply of $\mathrm{H}^{+}$ions [12,13]. A canonical correlation analysis showed that $\mathrm{pH}$ is one of the key factors affecting the rate of Feammox according to the analysis of 66 soil samples collected from different soil/sediments [14]. Moreover, Acidimicrobiaceae A6 has been identified as the only Feammox functional microorganism which can oxidize $\mathrm{NH}_{4}{ }^{+}$to $\mathrm{NO}_{2}{ }^{-}$, was also isolated from acidic wetland sediment and showed the highest $\mathrm{NH}_{4}{ }^{+}$oxidation rates at $\mathrm{pH} 4$ [11]. Nevertheless, there are three end-products $\left(\mathrm{N}_{2}, \mathrm{NO}_{2}{ }^{-}\right.$ and $\mathrm{NO}_{3}{ }^{-}$) in Feammox process (Equations (1)-(3)), and the effect of soil $\mathrm{pH}$ changes on Feammox pathways has not been thoroughly studied. According to thermodynamic calculations, Feammox to $\mathrm{N}_{2}$ is more likely to occur than the other two pathways (Equation (1)). Although the above conclusion is supported by recent studies, two other Feammox pathways with the end-products of $\mathrm{NO}_{2}{ }^{-}$and $\mathrm{NO}_{3}{ }^{-}$are noteworthy [6,7]. Especially in acidic soils/sediments, the activities of microorganisms such as denitrification and anammox are inhibited, and $\mathrm{NO}_{2}{ }^{-}$produced through Feammox is prone to accumulation, which can further lead to water pollution or greenhouse gas (e.g., $\mathrm{N}_{2} \mathrm{O}$ ) emission [12]. With the burning of fossil fuels and the extensive use of chemical fertilizers, the situation of soil acidification of cultivated land is gradually increasing [3]. Therefore, it is of great significance to explore the influence of soil $\mathrm{pH}$ changes on the rates and pathways of Feammox for controlling $\mathrm{N}$ loss in agricultural fertilization and reducing the risk of environmental pollution.

Red soil is one of the most important soil types in South China, and its high content of iron oxides lays a foundation for the occurrence of Feammox. Meanwhile, soil acidification is common in southern China, and it restricts crop growth and poses a severe threat to food security [3]. The main objectives of this study were to explore the effects of soil $\mathrm{pH}$ on the pathways of Feammox and the subsequent $\mathrm{N}$ transformation. The microbial communities of Feammox and their responses to soil $\mathrm{pH}$ also have been investigated.

\section{Materials and Methods}

\subsection{Isotopic Tracer Incubation}

Soil samples were collected from Yiliang County, Kunming, China $\left(24^{\circ} 47^{\prime} \mathrm{N}, 103^{\circ} 1^{\prime} \mathrm{E}\right)$ in November 2017. The average annual temperature of the site is $16.3^{\circ} \mathrm{C}$, and the annual precipitation is $1000 \mathrm{~mm}$. The region has a subtropical monsoon and the soil type is red soil, with long-term crop cultivation (mainly dryland crops). Five samples were collected within a range of $10 \times 10 \mathrm{~m}$ in the area $(0-10 \mathrm{~cm}$ depth) and then mixed together. The samples were transported to the laboratory in an icebox within $24 \mathrm{~h}$ and divided into 3 subsamples. One subsample was air-dried for analyzing the soil properties, the second subsample was used for isotope incubation, and the remaining subsample was stored in the freezer at $-80{ }^{\circ} \mathrm{C}$. The soil $\mathrm{pH}$ was $6.5 \pm 0.3$, and the water content was $48.8 \pm 0.2 \%$. The total $\mathrm{Fe}, \mathrm{TOC}, \mathrm{NH}_{4}{ }^{+}-\mathrm{N}$, and $\mathrm{NO}_{3}{ }^{-}-\mathrm{N}$ contents were $87.7 \pm 3.5 \mathrm{~g} \cdot \mathrm{kg}^{-1}, 70.0 \pm 0.8 \mathrm{~g} \cdot \mathrm{kg}^{-1}$, $40.9 \pm 0.3 \mathrm{mg} \cdot \mathrm{kg}^{-1}$, and $1.9 \pm 0.2 \mathrm{mg} \cdot \mathrm{kg}^{-1}$, respectively. $\mathrm{NO}_{2}{ }^{-}-\mathrm{N}$ was not detectable in the soil.

Isotope tracer incubation was conducted in an anaerobic glove box (Coy Laboratory Products, Grass Lake, MI, USA) filled with ultra-pure He using the procedure slightly modified from Ding et al. [7]. Prior to incubation, sterile anoxic deionized water was added to the 
soils at a ratio of 3:1 $(\mathrm{v} / \mathrm{w})$ and pre-incubated in an anaerobic glove box in the dark at $20{ }^{\circ} \mathrm{C}$ for 1 week to remove background $\mathrm{O}_{2}$ and $\mathrm{NO}_{\mathrm{x}}{ }^{-}$. After pre-incubation, the $\mathrm{O}_{2}$ and $\mathrm{NO}_{\mathrm{x}}{ }^{-}$ concentration was maintained at a low level $\left(<0.1 \mathrm{mg} \cdot \mathrm{L}^{-1}\right.$ and $<1 \mathrm{mg} \cdot \mathrm{kg}^{-1}$, respectively).

After pre-incubation, $21.5 \mathrm{~g}$ of homogenized slurries were transferred into $50 \mathrm{~mL}$ serum vials. The soil acidification process was simulated by manually adjusting the slurry $\mathrm{pH}$. Three $\mathrm{pH}$ groups $(5.0 \pm 0.1,6.5 \pm 0.1$, and $8.0 \pm 0.1)$ were set in the incubation, representing acidic, weakly acidic, and alkaline soil pH. $1 \mathrm{mM} \mathrm{NaOH}$ and $\mathrm{HCl}$ solutions were used to adjust the $\mathrm{pH}$ of the slurries to the preset values. The $\mathrm{pH}$ of the slurries was adjusted again to the set values after $12 \mathrm{~h}$ to reduce the influence of the soil acid-base buffer on the experiment. In each $\mathrm{pH}$ group, 3 treatments $(\mathrm{n}=5$ per treatment) were established to detect Feammox, namely (1) the control with only sterile anoxic deionized water; (2) ${ }^{15} \mathrm{NH}_{4} \mathrm{Cl}$ addition $\left({ }^{15} \mathrm{NH}_{4}{ }^{+}, 99\right.$ atom \%; Sigma-Aldrich, St. Louis, MO, USA); and (3) ${ }^{15} \mathrm{NH}_{4} \mathrm{Cl}$ and $\mathrm{C}_{2} \mathrm{H}_{2}$ addition $\left({ }^{15} \mathrm{NH}_{4} \mathrm{Cl}+\mathrm{C}_{2} \mathrm{H}_{2}\right)$. It has been reported that $\mathrm{C}_{2} \mathrm{H}_{2}$ (acetylene) can inhibit the reduction of $\mathrm{N}_{2} \mathrm{O}$ to $\mathrm{N}_{2}$ in denitrification and the activity of anammox bacteria $[15,16]$. The serum vials were then sealed with butyl rubber stoppers, and the headspace was exchanged with ultra-pure Ar for $5 \mathrm{~min}$. The ${ }^{15} \mathrm{NH}_{4} \mathrm{Cl}$ solution was prepared using sterile anoxic deionized water, and $0.5 \mathrm{~mL}$ of ${ }^{15} \mathrm{NH}_{4} \mathrm{Cl}$ solution was injected into the serum vials with sterile syringes so that the final concentration of ${ }^{15} \mathrm{NH}_{4} \mathrm{Cl}$ was $5 \mathrm{mM}$. For the $\mathrm{C}_{2} \mathrm{H}_{2}$ treatment, $7.5 \mathrm{~mL}$ of headspace gas in each vial was removed and replaced with $7.5 \mathrm{~mL}$ of $\mathrm{C}_{2} \mathrm{H}_{2}$ purified by $\mathrm{H}_{2} \mathrm{SO}_{4}$ to reach $30 \%(v / v) \mathrm{C}_{2} \mathrm{H}_{2}$ in the headspace [7]. Isotope tracer incubations were operated at $20^{\circ} \mathrm{C}$ in a constant temperature incubator, and all the vials were shaken vigorously to homogenize the treatment solutions daily. A set of vials was destructively sampled in an anaerobic glove box at $0,10,20$, and $30 \mathrm{~d}$. All the vials were shaken vigorously before sampling to equilibrate the gas between the dissolved and gaseous phases. Five milliliters of the headspace gas were extracted with sterile syringes and injected into a $12 \mathrm{~mL}$ pre-vacuumed glass tube (Labco Co., Ltd., High Wycombe, UK). The ${ }^{15} \mathrm{~N}$ enrichment in $\mathrm{N}_{2}$ was determined by isotope ratio mass spectrometry (Thermo Fisher Scientific, Waltham, MA, USA). The concentrations of ${ }^{15} \mathrm{~N}_{2}$ were calculated according to the production of $\mathrm{N}_{2}$ and its concentrations above the natural abundance [7].

The potential Feammox rate was conservatively estimated based on the difference in the ${ }^{30} \mathrm{~N}_{2}$ production between the treatment with ${ }^{15} \mathrm{NH}_{4} \mathrm{Cl}$ and the control. The $\mathrm{N}_{2}$ production rates were calculated from the changes in the $\mathrm{N}_{2}$ concentrations between two given times. The Feammox pathways were distinguished by adding $\mathrm{C}_{2} \mathrm{H}_{2}$, and the concentration of $\mathrm{C}_{2} \mathrm{H}_{2}$ used in this study was able to completely inhibit the denitrification and anammox processes [7]. The Feammox $-\mathrm{N}_{2}$ rate (Equation (1)) was estimated by the ${ }^{30} \mathrm{~N}_{2}$ production rate in the ${ }^{15} \mathrm{NH}_{4}{ }^{+}+\mathrm{C}_{2} \mathrm{H}_{2}$ treatment [6].

\subsection{Anaerobic Chemodenitrification Experiment}

In order to explore the effects of $\mathrm{pH}$ on the chemodenitrification reaction under anaerobic conditions, a series of experiments was conducted. The $\mathrm{Fe}^{2+}$ and $\mathrm{NO}_{2}{ }^{-}$solutions were prepared with anoxic deionized water. A $10 \mathrm{~mL} 5 \mathrm{mM} \mathrm{Fe}^{2+}$ solution was injected into $50 \mathrm{~mL}$ serum vials, and then the initial $\mathrm{pH}$ was adjusted to 4.0-7.0 using $\mathrm{NaOH}$ and $\mathrm{HCl}$ solutions. After exchanging the headspace with ultra-pure Ar, the serum vials were sealed with butyl rubber stoppers. An $\mathrm{NO}_{2}{ }^{-}$solution was added into the serum vials with sterile syringes to make the concentration of $\mathrm{NO}_{2}{ }^{-}$in the reaction system reach $2 \mathrm{mM}$. The serum vials with only $\mathrm{NO}_{2}{ }^{-}$or $\mathrm{Fe}^{2+}$ were set as controls at $\mathrm{pH}$ 5.0. The experiments were repeated in triplicate. The serum vials were incubated at $30{ }^{\circ} \mathrm{C}$ in a constant temperature incubator in the dark for $100 \mathrm{~h}$. The supernatant was extracted at setting time, and the concentration of the $\mathrm{NO}_{2}{ }^{-}$was determined by ion chromatography (Thermo Fisher Scientific, Waltham, MA, USA). 


\subsection{Physicochemical Analysis}

The soil $\mathrm{pH}$ was determined using a $\mathrm{pH}$ meter (Mettler-Toledo, Zurich, Switzerland), and the ratio of deionized water to soil was 2.5:1 $(v / w)$. The total organic $\mathrm{C}$ (TOC) content was determined by the potassium dichromate oxidation method [17]. The $\mathrm{NH}_{4}{ }^{+}$and $\mathrm{NO}_{\mathrm{x}}{ }^{-}$ were extracted with a $2 \mathrm{M} \mathrm{KCl}$ solution for $1 \mathrm{~h}$ and determined by a continuous-flow nutrient auto-analyzer (Skalar Analytic, Breda, The Netherlands). The total extractable $\mathrm{Fe}(\mathrm{III})$ and $\mathrm{Fe}(\mathrm{II})$ in the soil were determined according to the slightly modified method of Ding et al. [7]. Briefly, $1.0 \mathrm{~g}$ of soil was extracted with $5 \mathrm{~mL}$ of $0.50 \mathrm{M} \mathrm{HCl}$ and $5 \mathrm{~mL}$ of $0.25 \mathrm{M}$ hydroxylamine hydrochloride in $0.25 \mathrm{M} \mathrm{HCl}$ for $2 \mathrm{~h}$ at $30^{\circ} \mathrm{C}$ in an anaerobic glove box. The ferrozine method was used to measure the total Fe and Fe(II) contents [18]. The ${ }^{15} \mathrm{~N}$ enrichment in the $\mathrm{N}_{2}$ was determined by isotope ratio mass spectrometry (Thermo Fisher Scientific, Waltham, MA, USA).

\subsection{Microbial Community Analysis}

DNA samples were extracted from $1.0 \mathrm{~g}$ of soil slurry collected after $30 \mathrm{~d}$ of incubation and amplified using the primer pair 515F and 806R for the V4 region of the 16S rRNA gene as described by the manufacture's protocol. Sequencing was conducted at a commercial company (Majorbio, Shanghai, China). The microbial community functional profiles were predicted using PICRUSt (Phylogenetic Investigation of Communities by Reconstruction of Unobserved States). DNA samples were extracted from $1.0 \mathrm{~g}$ of soil slurry collected after 30 days' incubation using a Fast DNA SPIN Kit for soil (MP Biomedical, Solon, OH, USA), according to the manufacture's protocol. The quality and purity of the extracted DNA were determined using the NanoDrop-2000 spectrophotometer (NanoDrop Technologies, Wilmington, NC, USA) and then stored in the refrigerator at $-20^{\circ} \mathrm{C}$. The extracted DNA was amplified using the primer pair 515F and 806R for V4 region of the $16 \mathrm{~S}$ rRNA gene. PCRs were performed in a total volume of $30 \mu \mathrm{L}$ containing $15 \mu \mathrm{L} .2 \times$ Taq master Mix, $1 \mu \mathrm{L}$ Bar-PCR primer F (10 uM), $1 \mu \mathrm{L}$ Primer R $(10 \mu \mathrm{M}), 10-20 \mathrm{ng}$ Genomic DNA, dd $\mathrm{H}_{2} \mathrm{O}$ $\mathrm{H}_{2} \mathrm{O}$ added to $30 \mu \mathrm{L}$. The PCR program was: $94^{\circ} \mathrm{C}$ for 3 min (Initial steps), 28 cycles of $94{ }^{\circ} \mathrm{C}$ for $30 \mathrm{~s}$ (Melt), $53^{\circ} \mathrm{C}$ for $40 \mathrm{~s}$ (Anneal), $72{ }^{\circ} \mathrm{C}$ for $5 \mathrm{~min}$ (Extend). A mixture of the $16 \mathrm{~S}$ rRNA PCR products was used for sequencing on the Illumina Miseq platform. Sequencing was conducted at a commercial company (Majorbio, Shanghai, China).

The microbial community functional profiles were predicted by using PICRUSt (Phylogenetic Investigation of Communities by Reconstruction of Unobserved States). The $16 \mathrm{~S}$ rRNA gene sequences were compared in the KEGG database (www.genome.jp/kegg/ pathway.html, (accessed on 7 June 2018)) to analyze the relative abundance of the KEGG orthologous groups associated with the $\mathrm{N}$ cycle in metabolic pathways. The predicted functional data were clustered according to the abundance distribution of functional groups or the similarity between samples. The functional groups and samples were sorted according to the clustering results and then presented by the heat map. R-project was used for cluster analysis and heat map drawing (www.R-project.org, (accessed on 20 June 2018)).

\subsection{Statistical Analyses}

One-way analysis of variance and Pearson's correlation analysis were conducted using SPSS 22.0 (SPSS Inc., Chicago, IL, USA), and $p<0.05$ was set to denote the significance level. One-way ANOVA analyses were used to calculate the variance between obtained data under different $\mathrm{pH}$ values. Pearson's correlation analysis was performed to evaluate the relationships among the nitrite concentrations, Feammox rates, and Fe(III) reduction rates. The figures in this study were drawn using Origin 9.0 (Origin Lab, Northampton, MA, USA).

\section{Results and Discussion}

\section{1. pH-Dependent Feammox Rates and Pathways}

For all the $\mathrm{pH}$ groups, a significant amount of ${ }^{30} \mathrm{~N}_{2}$ was detected in the ${ }^{15} \mathrm{NH}_{4}{ }^{+}$and ${ }^{15} \mathrm{NH}_{4}{ }^{+}+\mathrm{C}_{2} \mathrm{H}_{2}$ treatments, whereas no ${ }^{30} \mathrm{~N}_{2}$ accumulated in the control (Figure $1 \mathrm{a}$ ). The 
${ }^{30} \mathrm{~N}_{2}$ production rates were significantly $(p<0.05)$ higher in the $5.0 \mathrm{pH}$ group than those in the 6.5 and $8.0 \mathrm{pH}$ groups, varying from $0.94 \pm 0.08 \mathrm{mg} \mathrm{N} \mathrm{kg}^{-1} \mathrm{~d}^{-1}$ in the $5.0 \mathrm{pH}$ group to $0.42 \pm 0.03 \mathrm{mg} \mathrm{N} \mathrm{kg}{ }^{-1} \mathrm{~d}^{-1}$ in the ${ }^{15} \mathrm{NH}_{4}{ }^{+}$addition treatments in the $8.0 \mathrm{pH}$ group. The variations in the ${ }^{29} \mathrm{~N}_{2}$ production rate with $\mathrm{pH}$ were identical to those of the ${ }^{30} \mathrm{~N}_{2}$. However, the ${ }^{29} \mathrm{~N}_{2}$ production rates were higher than those of the ${ }^{30} \mathrm{~N}_{2}$ in all the groups.

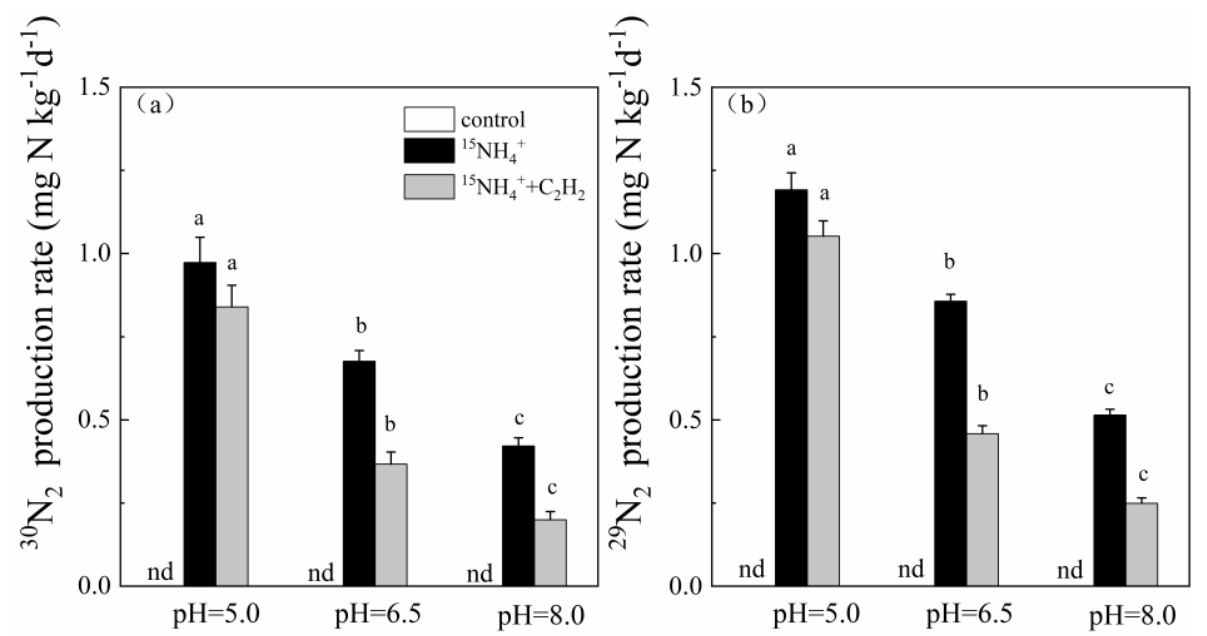

Figure 1. Mean headspace ${ }^{30} \mathrm{~N}_{2}$ (a) and ${ }^{29} \mathrm{~N}_{2}$ (b) production rates in the control, ${ }^{15} \mathrm{NH}_{4}{ }^{+}$and ${ }^{15} \mathrm{NH}_{4}{ }^{+}+\mathrm{C}_{2} \mathrm{H}_{2}$ treatments under three different $\mathrm{pH}$. The different small letters above the column denote statistically significant $(p<0.05)$ differences in different $\mathrm{pH}$ groups.

In this study, the soil slurries were strictly pre-incubated in an anoxic environment to remove indigenous molecular $\mathrm{O}_{2}, \mathrm{NO}_{3}{ }^{-}$, and $\mathrm{NO}_{2}{ }^{-}$. Strict anaerobic conditions were maintained during the ${ }^{15} \mathrm{~N}$ isotope incubation. Meanwhile, the $16 \mathrm{~S}$ rRNA sequencing results showed that no typical anammox bacteria were found in any of the experimental treatments. Therefore, the aerobic nitrification and anammox processes can be ruled out. Under these conditions, the Feammox to $\mathrm{N}_{2}$ (Equation (1)) and Feammox-generated ${ }^{15} \mathrm{NO}_{\mathrm{x}}{ }^{-}$(Equations (2) and (3)) reduction by denitrification are the only potential biological pathways for ${ }^{30} \mathrm{~N}_{2}$ production. Moreover, ${ }^{15} \mathrm{NH}_{4}{ }^{+}$promoted the $\mathrm{Fe}$ (III) reduction rates in the incubations, thereby further providing robust evidence for the occurrence of the Feammox process (Supplementary Figure S1). The Feammox rates in our incubation (0.42-0.94 mg N kg $\mathrm{m} \mathrm{d}^{-1}$ ) were of the same order of magnitude as those reported in natural environments (Figure 1 and Supplementary Table S1). The production rates of ${ }^{30} \mathrm{~N}_{2}$ and ${ }^{29} \mathrm{~N}_{2}$ in the $5.0 \mathrm{pH}$ groups (with and without $\left.\mathrm{C}_{2} \mathrm{H}_{2}\right)$ were significantly $(p<0.05)$ higher than those of the other $\mathrm{pH}$ groups, and there were higher initial $\mathrm{pH}$ values with lower Feammox rates (Figure 1). The significantly higher Feammox rates in the acid red soil than those in natural environments indicated that acid soil is more beneficial to the occurrence of Feammox (Supplementary, Table S1). However, it has been reported that a higher $\mathrm{pH}$ and lower Eh are beneficial to Feammox in mangrove wetlands [19], and the Feammox process also occurs in alkaline sediments (e.g., the intertidal wetlands of the Yangtze Estuary) [8]. The responses of the Feammox to soil $\mathrm{pH}$ fluctuations are not thoroughly understood. Fe oxides in the soil will release more soluble Fe(III) when the $\mathrm{pH}$ decreases [20], and there might be higher microbially reducible Fe(III) contents in acidic soil, which can be beneficial for providing more electron acceptors for the Feammox.

The thermodynamic calculations showed that the Feammox- $\mathrm{N}_{2}$ pathway could be conducted under a wide range of $\mathrm{pH}$ conditions, but the Feammox- $\mathrm{NO}_{2}{ }^{-}$pathway occurs only when the $\mathrm{pH}$ is less than 6.5 [6]. Previous studies have shown that Feammox- $\mathrm{N}_{2}$ is the main pathway of gaseous $\mathrm{N}$ loss in the Feammox process $(>50 \%)$, but the effect of soil $\mathrm{pH}$ on the Feammox pathways has been rarely reported. The Feammox- $\mathrm{N}_{2}$ pathway accounted for $47.4-86.2 \%$ of the total ${ }^{30} \mathrm{~N}_{2}$ loss in all the $\mathrm{pH}$ groups, and the proportion was significantly $(p<0.05)$ higher in the low-pH group (Supplementary Figure S2). The gaseous N loss ratio 
contributed by the Feammox coupled with denitrification (Feammox-denitrification) was $52.6 \%$ at a $\mathrm{pH}$ of 8.0. Although the PICRUSt results showed a significant increase in the denitrifying microbial abundance at a low $\mathrm{pH}$, the gaseous $\mathrm{N}$ loss rate from the Feammoxdenitrification pathway remained low in the $\mathrm{pH} 5.0$ group (Supplementary Figure S2). This may be due to the large amount of $\mathrm{NO}_{2}{ }^{-}$produced by Feammox under low $\mathrm{pH}$ conditions, which promoted the growth of denitrifying bacteria. However, the optimal $\mathrm{pH}$ value of the denitrifying bacteria was 7.0-9.0, and the activity of the denitrifying bacteria decreased under low $\mathrm{pH}$ conditions [12].

\subsection{Potential Transformation Pathways of $\mathrm{NO}_{2}{ }^{-}$}

The concentrations of $\mathrm{NO}_{3}{ }^{-}-\mathrm{N}$ and $\mathrm{NO}_{2}{ }^{-}-\mathrm{N}$ in the serum samples were measured at the end of the incubation (Figure 2). The concentrations of $\mathrm{NO}_{2}{ }^{-}-\mathrm{N}$ were significantly $(p<0.05)$ higher than that of the $\mathrm{NO}_{3}{ }^{-}-\mathrm{N}$ in each $\mathrm{pH}$ group. For the three different $\mathrm{pH}$ groups, the concentrations of $\mathrm{NO}_{2}{ }^{-}-\mathrm{N}$ in the ${ }^{15} \mathrm{NH}_{4}{ }^{+}$and ${ }^{15} \mathrm{NH}_{4}{ }^{+}+\mathrm{C}_{2} \mathrm{H}_{2}$ treatments at a pH of 5.0 were $4.84 \pm 0.46 \mathrm{mg} \cdot \mathrm{kg}^{-1}$ and $6.13 \pm 0.47 \mathrm{mg} \cdot \mathrm{kg}^{-1}$, respectively, which were significantly higher than those in the other $\mathrm{pH}$ conditions $(p<0.05)$. The linear regression analysis showed a positive correlation between the $\mathrm{NO}_{2}{ }^{-}-\mathrm{N}$ contents and the Feammox rate of ${ }^{30} \mathrm{~N}_{2}$ in all the treatments (Supplementary Figure S3), which further indicated that $\mathrm{NO}_{2}{ }^{-}$is an important intermediate product of the Feammox- $\mathrm{N}_{2}$ pathway (Equation (2)). $\mathrm{NO}_{2}{ }^{-}$is one of the primary end-products of Feammox in natural and wastewater treatment systems and plays a vital role in the transformation of the Fe cycle $[10,21,22]$. The Feammox$\mathrm{NO}_{2}{ }^{-}$pathway and the further transformation process of $\mathrm{NO}_{2}{ }^{-}$are worthy of attention.
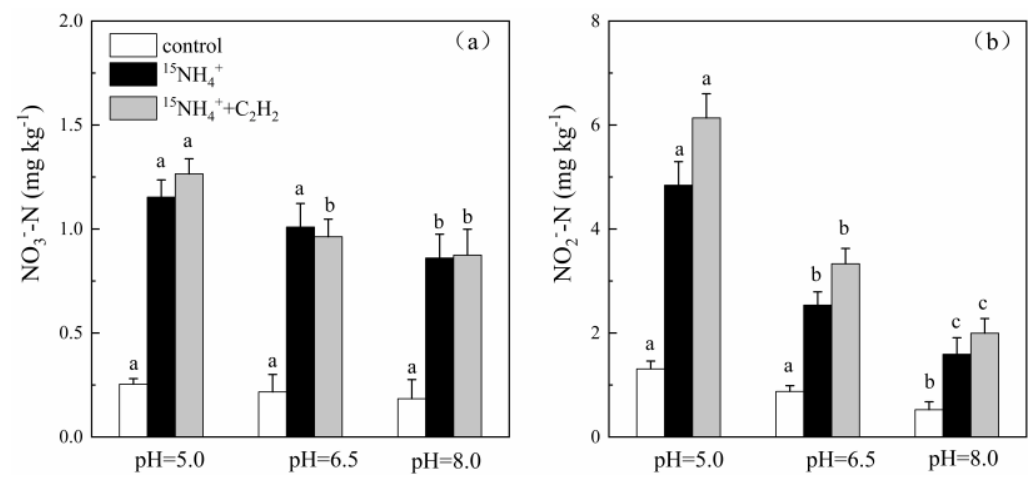

Figure 2. Concentration of $\mathrm{NO}_{3}{ }^{-}-\mathrm{N}(\mathbf{a})$ and $\mathrm{NO}_{2}{ }^{-}-\mathrm{N}(\mathbf{b})$ in anaerobic incubations on day 30. The different small letters above the column denote statistically significant $(p<0.05)$ differences in different $\mathrm{pH}$ groups.

Previous studies have shown that the Fe(III) reduction rates are significantly positively correlated with the $\mathrm{N}_{2}$ production rates $[6,7,9]$. The fluctuation in the $\mathrm{Fe}(\mathrm{III})$ reduction rate was not clear among the three $\mathrm{pH}$ groups in our study (Supplementary Figure S1). However, the ${ }^{30} \mathrm{~N}_{2}$ production rate was significantly increased in the $5.0 \mathrm{pH}$ groups. The gaseous $\mathrm{N}$ production rate in the ${ }^{15} \mathrm{NH}_{4}{ }^{+}+\mathrm{C}_{2} \mathrm{H}_{2}$ treatment was also significantly increased at a $\mathrm{pH}$ of 5.0. This meant that the chemodenitrification reaction occurred and played an important role in the $5.0 \mathrm{pH}$ groups because the biological reduction of $\mathrm{NO}_{\mathrm{x}}^{-}$was completely inhibited. It has been reported that $\mathrm{NO}_{2}{ }^{-}$can be reduced to $\mathrm{N}_{2}$ with $\mathrm{Fe}(\mathrm{II})$ through chemodenitrification under anaerobic conditions (Equation (4)), which may be one of the potential pathways of $\mathrm{N}_{2}$ loss in the Feammox process [21,23]. The kinetics of the chemodenitrification reaction under different $\mathrm{pH}$ values indicated that the $\mathrm{NO}_{2}{ }^{-}$reduction rates increased with the decrease in the $\mathrm{pH}$ (Figure 3). It has been demonstrated that chemodenitrification makes a greater contribution to $\mathrm{NO}_{2}{ }^{-}$decomposition in sterilized acid soil [24]. The increase in the $\mathrm{NO}_{2}{ }^{-}$reduction rate at a low $\mathrm{pH}$ may be due to the higher proportion of $\mathrm{HNO}_{2}$ in the liquid phase. The protonation of $\mathrm{NO}_{2}{ }^{-}$promotes the fracture of $\mathrm{N}-\mathrm{O}$, thereby resulting in a more robust oxidation of $\mathrm{HNO}_{2}$ than $\mathrm{NO}_{2}{ }^{-}$[25]. 
This confirmed that Feammox-generated Fe(II) was more likely to react with $\mathrm{NO}_{2}{ }^{-}$in the low-pH groups and further promote the $\mathrm{N}$ and Fe biogeochemical cycles.

$$
4 \mathrm{Fe}(\mathrm{II})+2 \mathrm{NO}_{2}{ }^{-}+8 \mathrm{H}^{+} \rightarrow 4 \mathrm{Fe}(\mathrm{III})+\mathrm{N}_{2}+9 \mathrm{H}_{2} \mathrm{O}
$$

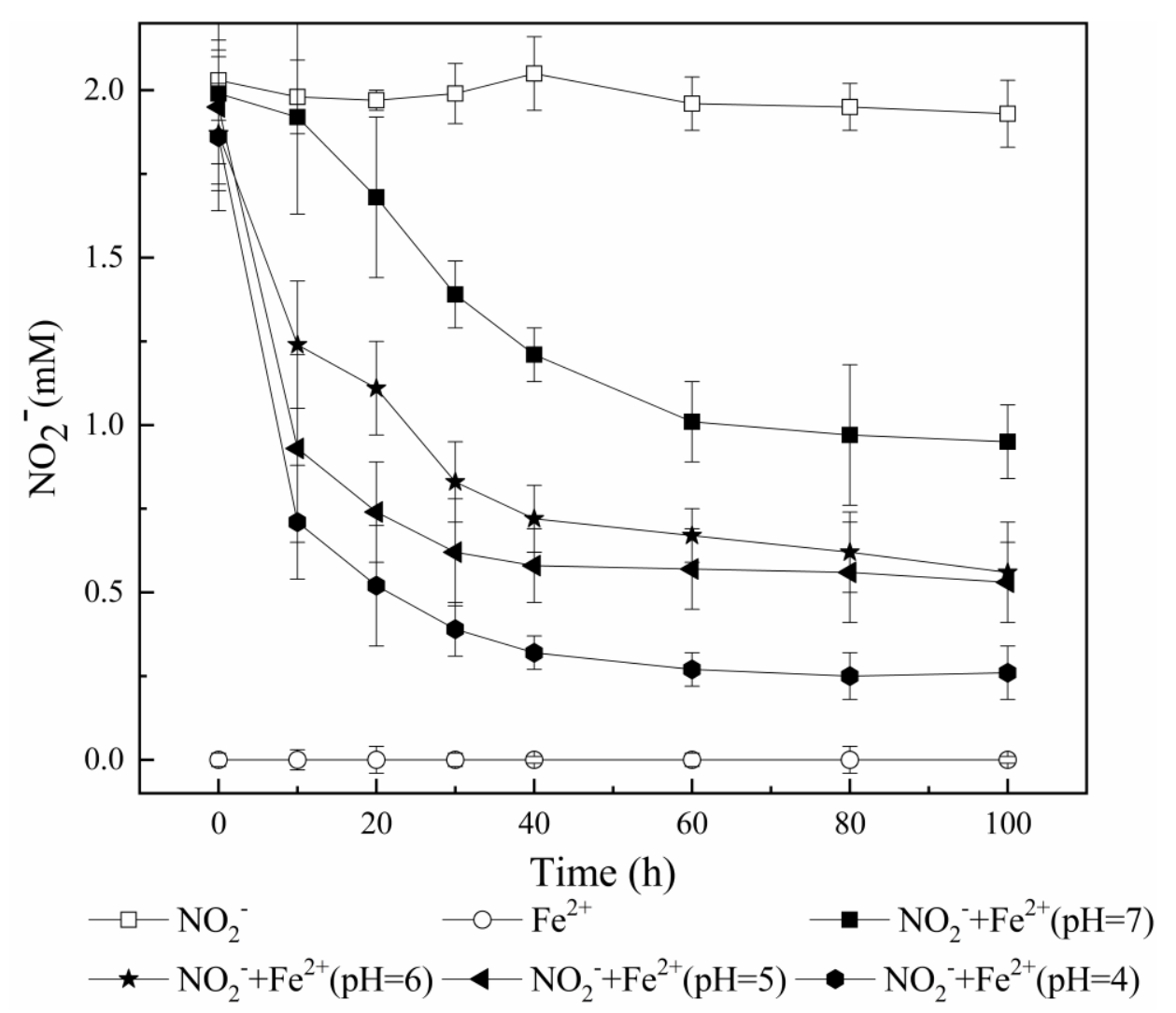

Figure 3. Anaerobic chemodenitrification at different $\mathrm{pH}$ values.

Amorphous Fe oxides in the soil will release more soluble Fe(III) when the $\mathrm{pH}$ decreases [20], which would promote the Feammox process and provide more Fe(II). Studies have shown that the surface of soil minerals can reaggregate the Fe(II) produced by microorganisms and accelerate the transfer of electrons to $\mathrm{NO}_{2}{ }^{-}$. Meanwhile, the $\mathrm{Fe}(\mathrm{II})$ adsorbed on the soil minerals has a higher oxidizability in the reaction between $\mathrm{Fe}(\mathrm{II})$ and $\mathrm{NO}_{2}{ }^{-}$ compared with that of dissolved $\mathrm{Fe}^{2+}$ [26]. Therefore, soil acidification will facilitate $\mathrm{Fe}$ (II) generation in the Feammox process and the chemical reduction of $\mathrm{NO}_{2}{ }^{-}$induced by $\mathrm{Fe}(\mathrm{II})$. The $\mathrm{Fe}(\mathrm{III})$ reduction was initiated by the Feammox process, and the generated Fe(II) was oxidized to $\mathrm{Fe}$ (III) by the $\mathrm{NO}_{2}{ }^{-}-\mathrm{N}$ reduction. Owing to the lack of continuous data on the $\mathrm{NO}_{2}{ }^{-} \mathrm{N}$ concentration, the extent of Feammox- $\mathrm{NO}_{2}{ }^{-}$could not be accurately calculated in our study.

\subsection{Evolution of the Microbial Community in Feammox}

Proteobacteria was the dominant phylum in the $5.0 \mathrm{pH}$ group in this study, with a relative abundance of 43.3-44.9\% (Figure 4). It has been reported that Ochrobactrum and Sphingomonas from Proteobacteria might contribute to a metals and $\mathrm{NO}_{\mathrm{x}}{ }^{-}$reduction, and are more abundant in acidic incubations [27-30]. The relative abundance of Firmicutes significantly increased $(p<0.05)$ at a $\mathrm{pH}$ of 5.0. Clostridium accounted for $6.68-15.59 \%$ of all the microorganisms, which was possibly because the genus is more suitable to more acidic environments. Clostridium species have been reported to reduce $\mathrm{Fe}(\mathrm{III})$ and $\mathrm{NO}_{3}{ }^{-}$ using acetate as an electron donor [31,32]. Our results also demonstrated that the Acidimicrobiaceae family had a higher abundance in the low-pH group. Although the genus information could not be obtained at the $97 \%$ OTU similarity level for Acidimicrobiaceae in 
this study, Acidimicrobiaceae has been classified as Fe-reducing and Feammox bacteria [22]. Acidimicrobiaceae bacterium $\mathrm{A} 6$ has been widely reported and identified as the functional microorganism responsible for the Feammox process [14,22].
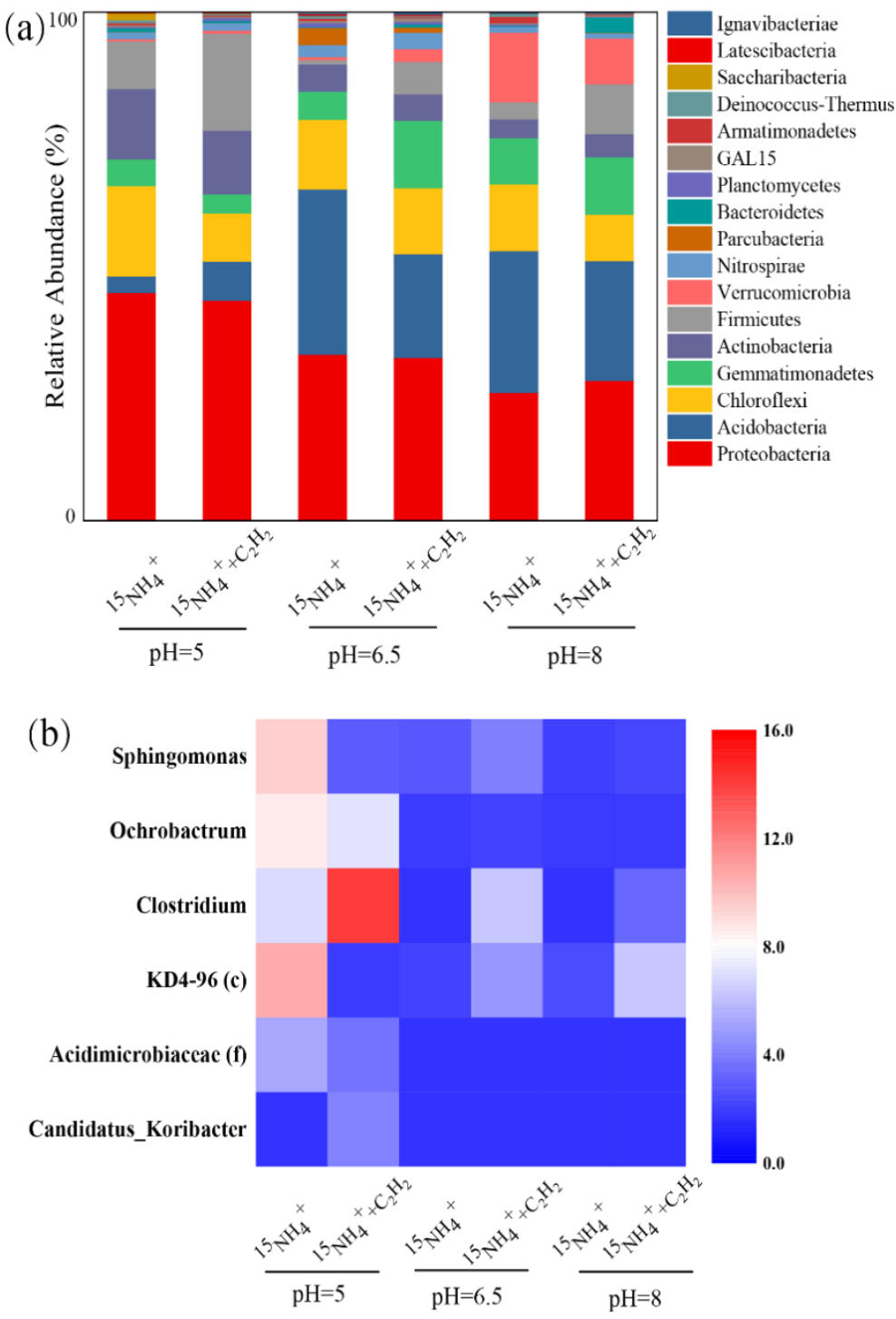

Figure 4. Relative abundance of main phyla (a) and genera (b) in the incubations.

Owing to the positive relationship between Fe-reducing bacteria and Feammox rates, researchers believe that Fe-reducing bacteria play a vital role in Feammox. The reported Fe-reducing bacteria have shown diverse communities in ecosystems, including Geobacter, Shewanella, Anaeromyxobacter, and Pseudomonas $[9,33,34]$. However, the Feammox- $\mathrm{N}_{2}$ functional microorganisms have not yet been identified. Geobacter and Shewanella were not detected in any of the treatments in this study. Geobacter would disappear during long-term Feammox culture [22]. In this study, the diversity of Fe-reducing bacteria changed significantly with the soil $\mathrm{pH}$. Ochrobactrum, Sphingomonas, and Clostridium may play significant roles in Fe reduction in the Feammox culture system at a $\mathrm{pH}$ of 5.0.

The effects of $\mathrm{pH}$ on the microbial community functional profiles were investigated using PICRUSt (Figure 5). The results showed that the relative abundances of the clusters of orthologous groups in the $5.0 \mathrm{pH}$ groups, which were associated with $\mathrm{NO}_{3}{ }^{-}$and $\mathrm{NO}_{2}{ }^{-}$ reduction or transformation (K00370-K00374, K00376, and K02305), were significantly higher than those at other $\mathrm{pH}$ values $(p<0.05)$. In this study, the detected $\mathrm{NO}_{\mathrm{x}}{ }^{-}$in the incubation was generated from the Feammox process. The low environmental $\mathrm{pH}$ promoted 
the Feammox- $\mathrm{NO}_{2}{ }^{-}$pathway (Equation (2)) and stimulated denitrifying microbial growth, which was consistent with the PICRUSt results. Although most denitrifiers have been reported in neutral and weakly alkaline environments, acidic environments can stimulate the growth of specific denitrifiers, such as Ochrobactrum and Clostridium [28,32]. In addition, the long-term culture of the Feammox system also showed that the abundance of the nirS and nirK genes increased, thereby demonstrating that denitrification was also active during the Feammox process $[14,22]$.

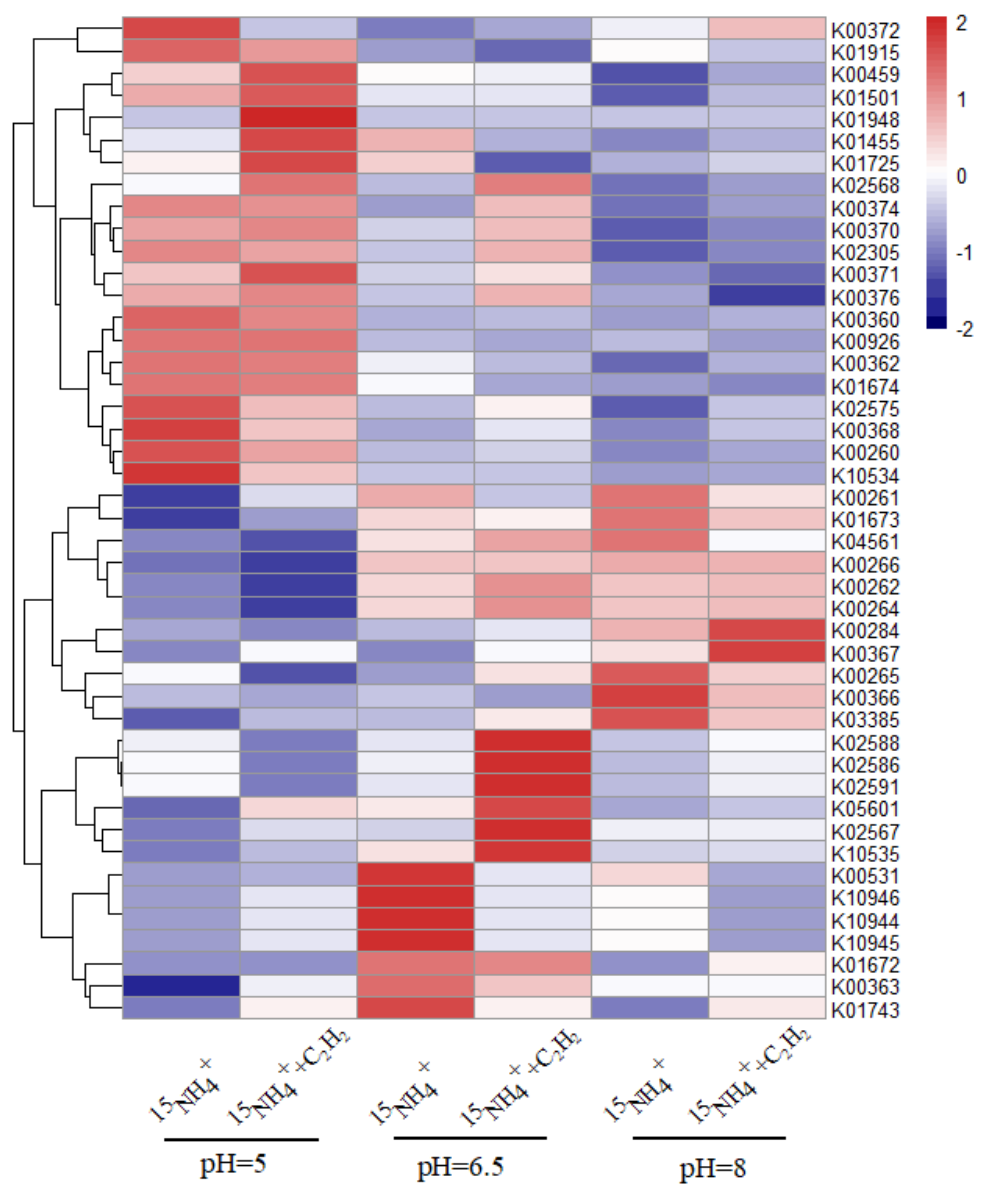

Figure 5. Heat map of KO (KEGG orthology) abundance associated with the nitrogen cycle based on PICRUSt.

\subsection{Environmental Implications}

Compared with that of previous studies, the high Feammox rate could be attributed to the low $\mathrm{pH}$ and high Fe content in the soil explored in this study. The soil was collected from the subtropical region of Southern China, which has a severe soil acidification problem. Based on the rates obtained from isotope incubations, the gaseous $\mathrm{N}$ loss via the Feammox process increased by $43.9 \%$ when the $\mathrm{pH}$ decreased from 6.5 to 5.0 in red soils. This result indicated that Feammox could be a vital pathway for $\mathrm{N}$ loss in acidic soils. However, the strict anaerobic conditions and high $\mathrm{NH}_{4}{ }^{+}$concentrations in the incubations possibly led to the overestimation of the Feammox rates, and precise evaluation is needed to perform in situ studies.

Theoretically, the oxidation of $1 \mathrm{~mol}$ of $\mathrm{NH}_{4}{ }^{+}$will consume 5-14 protons in the Feammox process, and the efficiency of neutralizing $\mathrm{H}^{+}$is much higher than that of lime, which was generally used to mitigate soil acidification (Equation (1)). However, the excessive lime application reduces the availability of nutrients in the soil, and additional agricultural measures are required to thoroughly mix the lime with the soil $[35,36]$. It has been reported that the $\mathrm{pH}$ value increases with the incubation and $\mathrm{NH}_{4}{ }^{+}$dosage in the Feammox process [10]. Similarly, the $\mathrm{pH}$ increased significantly at the end of our 
incubation in the $5.0 \mathrm{pH}$ group (data not shown). Therefore, the Feammox process may play an essential role in the acid-base equilibrium in soils. Feammox is theoretically feasible for remediating acidified soil, and its effects still need to be investigated through further experiments.

\section{Conclusions}

This study demonstrated that Feammox is a crucial gaseous $\mathrm{N}$ loss pathway in acidic upland soil (0.42-0.97 $\left.\mathrm{mg} \mathrm{N} \mathrm{kg}^{-1} \mathrm{~d}^{-1}\right)$, and the Feammox pathways were also affected by the soil $\mathrm{pH}$. Specifically, $\mathrm{N}_{2}$ was mainly directly generated by the Feammox process in acidic soils, while most of the $\mathrm{N}_{2}$ loss was attributed to Feammox-coupled denitrification in high-pH soils. The gaseous $\mathrm{N}$ loss through Feammox increased by $43.9 \%$ when the soil $\mathrm{pH}$ decreased from 6.5 to 5.0. In addition, $\mathrm{NO}_{2}{ }^{-}$is an important end-product of Feammox in acidic soil and is possibly reduced by Fe(II) through the abiotic/biotic process. Moreover, the relative abundances of Acidimicrobiaceae and Fe-reducing bacteria increased significantly under acidic conditions. This study provides experimental evidence of the influence of soil acidification on the Feammox pathways and new insights into the interaction between $\mathrm{N}$ application and soil acidification.

Supplementary Materials: The following are available online at https://www.mdpi.com/article/10 $.3390 /$ su131810393/s1, Figure S1: Fe(III) reduction rates measured in the isotope tracer incubations, Figure S2: The contribution of Feammox to $\mathrm{N}_{2}$ pathway $\left(\right.$ Feammox- $\mathrm{N}_{2}$ ) to gaseous $\mathrm{N}$ loss, Figure S3: Pearson's correlations of nitrite concentrations with both Feammox rates (a) and Fe(III) reduction rates (b), Table S1: Research on Feammox in natural environments.

Author Contributions: Conceptualization, D.M.; methodology, J.W.; formal analysis, J.X.; validation, S.X. and L.S.; formal analysis, D.M. and J.X.; investigation, D.M.; writing-original draft preparation, H.G.; writing—review and editing, D.M.; Wring-Review\& Editing; Z.Y.; funding acquisition, Z.Y., S.X. and L.S. All authors have read and agreed to the published version of the manuscript.

Funding: This research is financially supported by the National Natural Science Foundation of China (52070062 and U19A20108) and Hefei municipal design \& Research Institute Co., Ltd.

Institutional Review Board Statement: Not applicable.

Informed Consent Statement: Not applicable.

Data Availability Statement: The data are not publicly available due to privacy issue.

Acknowledgments: The authors would like to acknowledge National Natural Science Foundation of China. The authors would like to acknowledge Hefei municipal design \& Research Institute Co., Ltd.

Conflicts of Interest: The authors declare no conflict of interest.

\section{References}

1. Huang, J.; Xu, C.C.; Ridoutt, B.G.; Wang, X.C.; Ren, P.A. Nitrogen and phosphorus losses and eutrophication potential associated with fertilizer application to cropland in China. J. Clean. Prod. 2017, 159, 171-179. [CrossRef]

2. Yu, C.; Huang, X.; Chen, H.; Godfray, H.C.J.; Wright, J.S.; Hall, J.W.; Gong, P.; Ni, S.; Qiao, S.; Huang, G.; et al. Managing nitrogen to restore water quality in China. Nature 2019, 567, 516-520. [CrossRef]

3. Guo, J.H.; Liu, X.J.; Zhang, Y.; Shen, J.L.; Han, W.X.; Zhang, W.F.; Christie, P.; Goulding, K.W.T.; Vitousek, P.M.; Zhang, F.S. Significant Acidification in Major Chinese Croplands. Science 2010, 327, 1008-1010. [CrossRef] [PubMed]

4. Greaver, T.L.; Clark, C.M.; Compton, J.E.; Vallano, D.; Talhelm, A.F.; Weaver, C.P.; Band, L.E.; Baron, J.S.; Davidson, E.A.; Tague, C.L.; et al. Key ecological responses to nitrogen are altered by climate change. Nat. Clim. Chang. 2016, 6, 836-843. [CrossRef]

5. Zhu, Z.L. Research on soil nitrogen in China. Acta Pedol. Sinica. 2008, 45, 778-783.

6. Yang, W.H.; Weber, K.A.; Silver, W.L. Nitrogen loss from soil through anaerobic ammonium oxidation coupled to iron reduction. Nat. Geosci. 2012, 5, 538-541. [CrossRef]

7. Ding, L.J.; An, X.L.; Li, S.; Zhang, G.L.; Zhu, Y.G. Nitrogen loss through anaerobic ammonium oxidation coupled to iron reduction from paddy soils in a chronosequence. Environ. Sci. Technol. 2014, 48, 10641-10647. [CrossRef]

8. Li, X.; Hou, L.; Liu, M.; Zheng, Y.; Yin, G.; Lin, X.; Cheng, L.; Li, Y.; Hu, X. Evidence of Nitrogen Loss from Anaerobic Ammonium Oxidation Coupled with Ferric Iron Reduction in an Intertidal Wetland. Environ. Sci. Technol. 2015, 49, 11560-11568. [CrossRef] [PubMed] 
9. Ding, B.; Li, Z.; Qin, Y. Nitrogen loss from anaerobic ammonium oxidation coupled to Iron(III) reduction in a riparian zone. Environ. Pollut. 2017, 231, 379-386. [CrossRef] [PubMed]

10. Clément, J.; Shrestha, J.; Ehrenfeld, J.; Jaffe, P. Ammonium oxidation coupled to dissimilatory reduction of iron under anaerobic conditions in wetland soils. Soil Biol. Biochem. 2005, 37, 2323-2328. [CrossRef]

11. Huang, S.; Jaffe, P.R. Isolation and characterization of an ammonium-oxidizing iron reducer: Acidimicrobiaceae sp. A6. PLoS ONE 2018, 13, e0194007.

12. Tang, Y.; Zhou, C.; Ziv-El, M.; Rittmann, B.E. A pH-control model for heterotrophic and hydrogen-based autotrophic denitrification. Water Res. 2011, 45, 232-240. [CrossRef] [PubMed]

13. Huang, X.; Zhu-Barker, X.; Horwath, W.R.; Faeflen, S.J.; Luo, H.; Xin, X.; Jiang, X. Effect of iron oxide on nitrification in two agricultural soils with different $\mathrm{pH}$. Biogeosciences 2016, 13, 5609-5617. [CrossRef]

14. Huang, S.; Chen, C.; Peng, X.; Jaffé, P.R. Environmental factors affecting the presence of Acidimicrobiaceae and ammonium removal under iron-reducing conditions in soil environments. Soil Biol. Biochem. 2016, 98, 148-158. [CrossRef]

15. Jensen, M.M.; Thamdrup, B.; Dalsgaard, T. Effects of specific inhibitors on anammox and denitrification in marine sediments. Appl. Environ. Microbiol. 2007, 73, 3151-3158. [CrossRef] [PubMed]

16. Qin, S.P.; Hu, C.S.; Oenema, O. Quantifying the under estimation of soil denitrification potential as determined by the acetylene inhibition. Soil Biol. Biochem. 2012, 47, 14-17. [CrossRef]

17. Kalembasa, S.J.; Jenkinson, D.S. A comparative study of titrimetric and gravimetric methods for the determination of organic carbon in soil. J. Sci. Food Agric. 1973, 24, 1085-1090. [CrossRef]

18. Li, H.; Su, J.Q.; Yang, X.R.; Zhou, G.W.; Lassen, S.B.; Zhu, Y.G. Rna stable isotope probing of potential feammox population in paddy soil. Environ. Sci. Technol. 2019, 53, 4841-4849. [CrossRef]

19. Guan, Q.S.; Cao, W.Z.; Wang, M.; Wu, G.J.; Wang, F.F.; Jiang, C.; Tao, Y.R.; Gao, Y. Nitrogen loss through anaerobic ammonium oxidation coupled with iron reduction in a mangrove wetland. Eur. J. Soil Sci. 2018, 69, 732-741. [CrossRef]

20. Schwertmann, U.; Cornell, R.M. Iron Oxides in the Laboratory. Soil Sci. 1991, 156, 281-282. [CrossRef]

21. Yang, Y.; Xiao, C.; Lu, J.; Zhang, Y. Fe(III)/Fe(II) forwarding a new anammox-like process to remove high-concentration ammonium using nitrate as terminal electron acceptor. Water Res. 2020, 172, 115528. [CrossRef] [PubMed]

22. Huang, S.; Jaffé, P.R. Characterization of incubation experiments and development of an enrichment culture capable of ammonium oxidation under iron-reducing conditions. Biogeosciences 2015, 12, 769-779. [CrossRef]

23. Tai, Y.L.; Dempsey, B.A. Nitrite reduction with hydrous ferric oxide and Fe(II): Stoichiometry, rate, and mechanism. Water Res. 2009, 43, 546-552. [CrossRef] [PubMed]

24. Lim, N.Y.N.; Frostegård, A.; Bakken, L.R. Nitrite kinetics during anoxia: The role of abiotic reactions versus microbial reduction. Soil Biol. Biochem. 2018, 119, 203-209. [CrossRef]

25. Wimmer, F.L. Book Review: Inorganic Chemistry, 2nd ed.; Shriver, D.F., Atkins, P.W., Langford, C.H., Eds.; SAGE Journals: New York, NY, USA, 1995; pp. 599-600.

26. Lu, Y.; Lu, X.; Shu, W.; Zhou, J.; Qian, G. Microbial mediated iron redox cycling in fe (hydr)oxides for nitrite removal. Bioresour. Technol. 2016, 224, 34-40. [CrossRef]

27. Sultan, S.; Hasnain, S. Reduction of toxic hexavalent chromium by Ochrobactrum intermedium strain SDCr-5 stimulated by heavy metals. Bioresour. Technol. 2007, 98,340-344. [CrossRef]

28. Lei, X.; Jia, Y.; Chen, Y.; Hu, Y. Simultaneous nitrification and denitrification without nitrite accumulation by a novel isolated Ochrobactrum anthropic LJ81. Bioresour. Technol. 2019, 272, 442-450. [CrossRef]

29. Zhou, J.; Sun, Q.; Chen, D.; Wang, H.Y.; Yang, K. Ochrobactrum anthropi used to control ammonium for nitrate removal by starch-stabilized nanoscale zero valent iron. Water Sci. Technol. 2017, 76, 1827-1832. [CrossRef] [PubMed]

30. Doi, Y.; Takaya, N.; Takizawa, N. Novel Denitrifying Bacterium Ochrobactrum anthropi YD50.2 Tolerates High Levels of Reactive Nitrogen Oxides. Appl. Environ. Microb. 2009, 75, 5186-5194. [CrossRef]

31. Jiang, S.; Park, S.; Yoon, Y.; Lee, J.H.; Wu, W.M.; Nguyen Phuoc, D.; Sadowsky, M.J.; Hur, H.G. Methanogenesis Facilitated by Geobiochemical Iron Cycle in a Novel Syntrophic Methanogenic Microbial Community. Environ. Sci. Technol. 2013, 47, 10078-10084. [CrossRef]

32. Xu, Y.; He, Y.; Feng, X.; Liang, L.; Xu, J.; Brookes, P.C.; Wu, J. Enhanced abiotic and biotic contributions to dechlorination of pentachlorophenol during Fe(III) reduction by an iron-reducing bacterium Clostridium beijerinckii Z. Sci. Total Environ. 2014, 473, 215-223. [CrossRef] [PubMed]

33. Ding, J.; Zhang, Y.; Quan, X.; Chen, S. Anaerobic biodecolorization of AO7 by a newly isolated Fe(III)-reducing bacterium Sphingomonas strain DJ. J. Chem. Technol. Biot. 2015, 90, 158-165. [CrossRef]

34. Ding, B.; Luo, W.; Qin, Y.; Li, Z. Effects of the addition of nitrogen and phosphorus on anaerobic ammonium oxidation coupled with iron reduction (Feammox) in the farmland soils. Sci. Total Environ. 2020, 737, 139849. [CrossRef] [PubMed]

35. Cai, Z.; Wang, B.; Zhang, L.; Wen, S.; Xu, M.; Misselbrook, T.H.; Carswell, A.M.; Gao, S. Striking a balance between N sources: Mitigating soil acidification and accumulation of phosphorous and heavy metals from manure. Sci. Total Environ. 2021, 754, 142189. [CrossRef] [PubMed]

36. Xu, D.; Carswell, A.; Zhu, Q.; Zhang, F.; de Vries, W. Modelling long-term impacts of fertilization and liming on soil acidification at Rothamsted experimental station. Sci. Total Environ. 2020, 713, 136249. [CrossRef] 